\title{
Urdimento
}

\section{O CORPO INVISÍVEL: TEATRO E TECNOLOGIAS DA IMAGEM ${ }^{1}$}

\author{
Óscar Cornago Bernal ${ }^{2}$
}

\section{Resumo}

O texto aborda a relação do teatro com as novas tecnologias e realiza uma aproximação entre o espetáculo teatral e os modelos de representação tais como cinema, televisão, vídeo e Internet. Discutindo ainda um pensamento essencialista que perceberia uma identidade fixa, uma essência característica de cada linguagem, o texto propõe analisar das zonas de intercâmbio entre as linguagens abordadas diferenciando dois grandes níveis de influência entre os novos meios e o teatro: um nível mais profundo culturalmente e menos explícito, e outro mais visível com uma vontade artística expressa, que costuma traduzir-se na utilização de aparatos midiáticos na cena.

Palavras-chave: teatro e tecnologias, mídia e encenação, imagem.

\begin{abstract}
This paper addresses the relationship between Theatre and New Technologies, suggesting a potential integration between Theatre and Media such as Cinema, Television, Video and Internet. The study discusses the ways in which electronic media became an integral part of numerous performances, stressing underlying strategies common both to Media and Art. Suggests that there are at least two levels of influence between media technologies and Theatre: a deeper and less explicit stage, where prospective interaction is very restrained, and a broaden evident stage, where new media is converted into an integral feature of a theater performance.
\end{abstract}

Keywords: theater and technologies, media and performance, image.

A relação do teatro com as novas tecnologias é um tema que se presta com facilidade a enfoques apocalípticos em torno ao futuro do teatro e sua sempre questionada sobrevivência na sociedade dos meios. Uma aproximação distanciada e menos catastrófica nos mostra, no entanto, que o teatro, como técnica da representação, esteve sempre aberto aos avanços que têm permitido ampliar suas possibilidades de expressão. Desde o começo introduziu engenhos técnicos para fazer aparições desde as alturas, vôos na cena, desaparecimentos pelo solo ou estranhas mutações que assombraram ao público. Tão pouco deixou de adaptar-se com rapidez às diferentes técnicas de iluminação, nem às crescentes formas de se conseguir maior mobilidade na cena. Assim chegamos ao século $\mathrm{XX}$, quando se fez possível a gravação da voz e de imagens, o que deu lugar ao

${ }^{1}$ Tradução de André Carreira.

º́scar Cornago

Bernal é pesquisador do Instituto de la Lengua Española do Consejo Superior de Investigaciones Científicas (Madri Espanha). Entres seus livros encontram-se $L a$ Vanguardia teatral en España (1965-1975); Del ritual al juego; Discriso teórico y puesta en escena en los años sesenta: la encrucijada de los realismos e Pensar la teatralidad: Migual Romero Esteo y las estéticas de la modernidad. 


\section{Urdimento}

${ }^{3}$ A relação televisãoteatro não foi sempre imposta desde o meio televisivo; no começo a televisão, como fez antes o cinema, teve que recorrer aos produtos teatrais como ponto de partida para sua programação (AA. VV. 1979). Esslin (1970) afirma que quase todos os dramaturgos ingleses dos anos cinqüenta e sessenta fizeram trabalhos para a televisão, quando esta ainda não tinha desenvolvido uma linguagem tão específica. rádio, à fotografia e ao cinema, instrumentos que as vanguardas não tardaram em incorporar. A partir deste enfoque, as tecnologias da imagem representam um capítulo a mais, o último grande capítulo, na história do teatro.

\section{Modelos de representação dominantes: cinema, televisão, vídeo, internet?}

Muito se tem falado da influência e das relações do cinema com outros gêneros; sem dúvida, sua rápida conquista de uma prestigiada condição artística, e não meramente documental, o situou na frente do horizonte estético do século XX. A história da televisão tem sido muito diferente; sua estreita relação com a realidade tem negado-lhe uma entrada no parnaso das artes, e esta teve que esperar o invento do gravador no final dos anos sessenta e o correspondente desenvolvimento da técnica do vídeo. Posteriormente, a televisão digital e as infinitas janelas abertas pela Internet não fizeram mais que levar ao extremo uns comportamentos culturais antecipados de algum modo no funcionamento da televisão. Neste sentido, uma menor repercussão explícita destes meios nas artes leva a pensar que sua influência mediática pudesse ficar reduzida ao mundo cultural não especificamente estético, enquanto que se seguiu falando do cinema como a linguagem paradigmática do século XX.

No entanto, a influência do cinema como meio dominante, a linguagem modeladora primaria - utilizando a terminologia de Lotman -, teve seu apogeu nos anos cinquenta e começou a mudar de signo na década seguinte, o que não quer dizer que deixasse de ser um referente artístico de primeira ordem. Isto nos permite dar um giro à equação e começar a pensar, por exemplo, na crescente influência do paradigma televisivo na tela grande. A influência estrutural do cinema na dramaturgia se faz visível nos anos cinqüenta e sessenta, por exemplo, no teatro realista norte americano de Tennessee Williams ou Arthur Miller, cujo marcado acento narrativo facilitou o acesso ao cinema; mas a partir dos anos sessenta se impõe de maneira cabal, com a eficácia que somente têm os meios que em algum momento passaram por transparentes - naturais -, outro modelo de comunicação diverso que é a televisão, o grau zero da "midialidade", que através das séries e outros programas de pequeno formato, seus produtos mais famosos, proporá um esquema de construção dramática a numerosos autores dos anos oitenta e noventa, familiarizados por outro lado com este meio pelo seu trabalho profissional, como antes haviam estado, ainda que em menor medida, com o cinema ${ }^{3}$.

Diferentemente do tempo narrativo e distante no que nos submerge o cinema, a televisão propõe um ritmo rápido e entre cortado, uma sensação de proximidade e quase de intimidade (para o que contribui o novo espaço de recepção: a sala de estar ou o quarto de dormir) e o aparente protagonismo do 
espectador, no sentido de que este pode decidir a interrupção ou a mudança de emissão e inclusive a participação nela através da Internet e do telefone. Esta e outras características, levadas ao extremo pelo desenvolvimento posterior da tecnologia digital e, finalmente, ainda que já com novas implicações, da internet, vão constituir um paradigma profundamente teatral e performativo por sua sensação de imediatez, o aqui e agora do estúdio televisivo (o "ao vivo"), a presença explícita do público e seu aparente caráter coletivo; um modelo que será exportado a outras práticas estéticas (GÖTTLICH, NIELAND y SCHATZ, 1998; BREA, 2002; CORNAGO BERNAL, 2002). A pergunta que vai guiar este ensaio é a reação da própria cena, espaço da representação por excelência, ante uma série de tecnologias capazes de criar a ilusão de um novo teatro, o teatro mediático, mais crível, imediato e real, mais interativo e emocionante em muitos casos do que a cena real; um teatro mais real que a realidade, diria Baudrillard.

Por outro lado, o desenvolvimento dos meios não pode ser visto de forma desconexa, nem tão pouco acidental. Comumente, não é difícil perceber o nascimento de um meio como continuação, ou resposta a uma série de proposições que já estavam formulados previamente. Deste modo, a fotografia e o cinema vieram a preencher o desejo extremo de realismo e verossimilhança antecipado no romance ou no teatro. Dentro do espaço orgânico de uma cultura cada linguagem ocupa um lugar, e o nascimento, transformação ou desaparecimento de uma obriga a uma redistribuição do espaço em função das restantes. O fato é que cada movimento - ou melhor dito: esse movimento constante no qual estão inscritas todas as linguagens dentro de uma cultura - nos descreve forças de transformação e linhas de evolução que definem um período da história. Desde esta perspectiva, devemos nos perguntar também sobre os princípios estéticos que explicam o aparecimento e desenvolvimento extremo deste modelo de comunicação, de caráter imediato, fragmentário e interativo, que caracterizou a segunda metade do século XX, e dando um passo além - como dissemos anteriormente -, analisar em que medida o teatro previu e como respondeu as proposições e necessidades estéticas comparáveis.

A explosão midiática explicitou a importância de cada instrumento, de cada meio, dentro de uma cultura, dando lugar a uma perspectiva de análise conhecida como a teoria e história dos meios. Este enfoque fez que proliferassem as análises comparadas entre distintos gêneros já nos oitenta, o que introduziu um giro fascinante no estudo das artes, que até então tinham buscado entender-se desde seus traços essenciais, para analisá-las agora não na determinação essencialista de cada linguagem, senão na análise das zonas de intercâmbio entre cada uma delas; se trataria, portanto, de chegar a um conhecimento de cada linguagem, mas não desde seus centros e fundamentos, senão desde sua periferia, desde seus limites exteriores e espaços de indefinição, esse espaço onde a poesia se cruza com a pintura ou o teatro com a televisão. 


\section{Urdimento}

Sob esta aproximação os diferentes gêneros deixam de ser entendidos por um prisma belicista como eternos rivais, dado que o interessante seria agora iluminar os espaços de contato e diálogo de uns com outros (PAVIS, 2003: $61 \mathrm{ss}$.). Este recorte tem caracterizado igualmente as práticas artísticas nas últimas décadas, com a intensificação das relações entre campos diversos, normalizando uma atitude própria das vanguardas. Tal contato cada vez mais fluído permitiu a cada arte entender seus recursos específicos desde as outras e desenvolvê-los graças ao diálogo com outras formas de expressão; o teatro sonhando com ser cinema, o cinema com ser teatro, a televisão cada vez mais teatral ou a cena cada vez mais televisiva são fenômenos que enriqueceram cada um destes meios desde um olhar externo, ou em outras palavras: entender o teatro desde o que não é teatro, desde o cinema, a televisão, o vídeo ou Internet, se reverteu em um enriquecimento da maneira de fazer e conceber o processo cênico, sendo em muitos casos este tipo de práticas limiares, abertas a seu questionamento desde um olhar não especificamente cênico, as que têm dado lugar às peças de maior interesse. Respondendo a esta nova situação midiática, a cena moderna se revela como um espaço de contrastes e choques, caracterizado pela diversidade de olhares e formas de construção.

Neste ponto, podemos adiantar que o tipo de relações que vamos analisar a continuação não se reduz à utilização em cena de uma tela ou umas quantas projeções com os fins mais diversos. O tema das influências entre umas e outras linguagens é sempre complicado, porque somente algumas dessas influências se desenvolvem de modo explícito e consciente, enquanto que as repercussões mais profundas têm lugar em um plano menos visível. Neste sentido, a tese da qual partimos é que cada meio de expressão supõe algo mais que uma linguagem artística, na realidade implica um modo diferente de (nos) representar a realidade, de ter acesso ao mundo e perceberlo; consiste, em uma palavra, em um novo enfoque epistemológico, outra forma de conhecimento (representação) do mundo, e, portanto, um tipo de relação diferente do sujeito com o outro (POSTMAN, 1987; MCLUHAN y POWERS, 1996; FISCHER-LICHTE, 2001). Considerando isto se pode diferenciar dois grandes níveis de influência entre os novos meios e o teatro: a) um nível mais profundo culturalmente e menos explícito, e b) outro mais visível com uma vontade artística expressa, que costuma traduzir-se na utilização de aparatos midiáticos. Dentro deste último nível é possível, por sua vez, distinguir uma utilização mais casual ou tangencial, que não afeta a proposta estrutural da peça, e outro emprego profundo que sim determina a proposta dramatúrgica, que propõe uma reflexão sobre os diferentes modos de comunicação. Esta classificação não define compartimentos estanques, senão que se trata de uma proposta metodológica que nos permite mover-nos por este intrincado mundo de relações, diferenciando diálogos situados em níveis distintos. Nos tópicos 
III e IV deste texto se darão alguns exemplos de ambos enfoques, mas antes disso, devemos começar estabelecendo o eixo central desde o qual a cena se aproxima aos outros meios, sem deixar por isso de ser teatro: a presença do corpo frente a sua ausência midiática.

\section{O corpo invisível}

Este eixo (presença-ausência) não somente delimita um traço essencial da relação da cena com a imagem midiatizada, senão que ao mesmo tempo aponta a diferença que faz com que o teatro siga sendo teatro: a relação ator-espectador em um espaço e um tempo compartilhados por ambos. Como adiantamos acima, o aparecimento de novos meios vem comumente ligado a certos debates estéticos presen,tes já no ambiente cultural prévio. Do ponto de vista teatral, a discussão em torno ao corpo do ator, a reivindicação de seu caráter físico, sensorial e performativo, suas possibilidades expressivas e (modos de) comunicação imediata com o espectador têm sido alguns dos motores da renovação cênica desde as vanguardas históricas. Nos anos sessenta se recuperam e se assimilam estas posições, que serão iluminadas e contrastadas uma década depois graças à crescente utilização de equipamentos midiáticos. Com o barateamento dos equipamentos áudio visuais a possibilidade de introduzi-los na cena se incrementou até formar parte, a partir dos anos setenta, do repertório de linguagens cênicas.

\section{O olhar delega aos aparelhos e ao corpo se desmaterializa}

A percepção do espectador e a disposição na qual este é situado é radicalmente distinta quando se vê frente a realidades, como corpos e objetos, ou frente a imagens que representam essas realidades. A imagem projetada carece de realidade para além de um jogo de luzes e sombras e do aparelho que as projeta; ainda que seja necessário distinguir entre imagens cinematográficas e imagens de vídeo, assim como é diferente se sua projeção se faz sobre uma tela plana dissimulada na cena ou em um monitor de televisão a vista do público (ZUNZUNEGUI, 1995; ALCÁZAR, 1998; GONZÁLEZ REQUENA, 1999). As primeiras, as projeções cinematográficas, têm uma capacidade maior de evocar ilusões fictícias e reconstruir um tempo diferido, são mais perfeitas; as segundas, as imagens de vídeo, e conseqüentemente, a maior parte das televisadas, apontam para um maior grau de realidade e imediatez, fazem visível sua materialidade e talvez por isso também sua imperfeição, inclusive qualitativa (ainda que isto tenha mudado com a técnica digital); seriam, em uma palavra, mais teatrais. Não obstante, em um e outro caso uma imagem é sempre algo fechado e perfeito em si mesmo, uma totalidade situada em um tempo distinto ao do espectador (que se encontra, portanto, desligado delas e sem responsabilidade direta); não esconde nada detrás e nada o incomoda, 


\section{Urdimento}

${ }^{4}$ Certamente há retransmissões de televisão chatas, e não poucas, mas inclusive nestes casos parece que a monotonia seja mais leve frente a uma tela; nada chateia tanto como uma realidade tratando de passar por ficção quando o efeito não é alcançado, e isto não é fácil de se conseguir com atores de carne e osso em uma sociedade hiper-especializada na produção de ficções.

${ }^{5}$ Não é de se estranhar que alguns dos grandes criadores, como Gordon Craig ou Tadeusz Kantor, ante as dificuldades de transformar tal excesso em uma realidade estética controlada, tenham protestado contra este componente que da ao teatro sua única especificidade. Já Diderot reconheceu o paradoxo de que 0 ator, somente como uma máquina fria, era capaz de significar 0 vivo. tudo está preparado para sua exibição e não há nada mais além do que se vê na tela, mas tão pouco deve aspirar a descobrir algo mais; está em si mesma acabada (LEHMANN, 1999: 401-448). O espectador se sente psiquicamente relaxado e comprazido ante uma realidade projetada, isto é, liberada de sua contingência imediata, de presente e futuro, e portanto desligada de seu eu como sujeito moral. As imagens, como as ilusões, não decepcionam, ao menos enquanto não se queira convertê-las em realidade, mas tão pouco dão mais do que mostram, somente têm a cara que vemos, detrás não há nada, tão pouco nada que possa oferecer resistência à percepção.

Os objetos materiais da cena e sobre tudo o corpo do ator despertam no público emoções menos ilusórias, pois se trata de realidades em um tempo presente compartilhado com o espectador, mais intransitivas em seu poder de evocação, por isso também menos tranqüilizadoras, e talvez em alguns casos mais monótonas ao ter menos capacidade de engano. É mais difícil manter a atenção do público na cena; ante uma peça medíocre sua atenção subirá quando se encontre surpreendido - deveríamos dizer: gratamente surpreendido? por umas atraentes imagens que o façam mergulhar, ainda que somente seja por uns minutos, em um mundo de ficção, mas realmente verossímil, e sua atenção se verá novamente traída quando a projeção acabe e deva voltar à tosca realidade da cena ${ }^{4}$. No lado positivo da balança, temos uma presença material e física da que carece o signo virtual. O signo cênico remete também a uma ausência (o ator faz como se fosse Hamlet, que na verdade não está ali), mas conta com uma importante presença: o significante sim está ali, de forma física, na atitude performativa, e não apenas como projeção de luzes. $\mathrm{Na}$ cultura das imagens, com uma forma de ver e entender conformada pela epistemologia televisiva, essa presença imediata do signo supõe um excesso de realidade que pode ser inclusive incomodo ou até mesmo grosseiro. $\mathrm{O}$ corpo do ator, sua presença viva, implica um plus com o que o criador, já seja o diretor ou o próprio ator, deve trabalhar para chegar a incomodá-lo ${ }^{5}$, mas também supõe um excesso para o espectador por desentoar radicalmente com a estética midiática perfeitamente recortada segundo as necessidades. $\mathrm{O}$ corpo se levanta como um elemento excessivo, estratégia de resistência a uma realidade pré-fabricada; não se trata de uma imagem acabada e perfeita, senão que está fazendo-se em cada instante, sempre no processo de seu presente contínuo. Esse excesso supõe um constante perigo de traição à obra de arte ou às expectativas culturais do público com relação ao perfeito e acabado, mas também uma abertura para a única verdade, ao imprevisto e efềmero, ao excessivo, uma emoção imediata e incerta causada pelo que está ai a diante, a inquietação ante uma realidade que por ser artística não deixa de ser real, ou inclusive mais real que a realidade - como também quis Artaud -, mas que mantém a percepção em um constante caminho de busca. 


\section{Urdimento}

As tecnologias da imagem aplicadas à cena tem contribuído para fazer mais visíveis estas diferenças, denunciando de maneira quase incômoda esse excesso de presença sobre o qual se coloca o teatro, sua possibilidade de construir um tempo real compartilhado com o espectador. As atitudes dos distintos meios têm sido diversas: as linguagens televisivas, o vídeo a Internet, têm tratado de emular essa imediatez aparentemente espontânea, essa presença além do fingimento, enquanto que o cinema, pelo menos no seu período clássico, não deixou de gozar com a perfeição da ficção bem acabada, opção que tem sido contestada por correntes mais experimentais ${ }^{6}$. Desde o teatro, as posturas se estendem igualmente em um amplo leque, entre a aceitação da ficção, por outro lado inevitável, aproximando-se a modelos cinematográficos ou televisivos (re)construídos agora desde a realidade cênica, até a negação de tudo que é ficcional a favor das presenças imediatas, igualmente inevitáveis, não somente dos atores, senão também de telas, monitores e aparelhos de gravação. Ambas posturas não são, no entanto, contrárias, senão que se conjugam dando lugar a algumas das propostas mais interessantes das últimas três décadas.

\section{A cena ante os modelos culturais midiáticos}

Inclusive sem a utilização destes meios, a cena da segunda metade do século XX teve que reagir ante uns modos dominantes de percepção da realidade determinados pelas novas tecnologias. Por muito à margem que se quisesse estar destas (as novas tecnologias), é inevitável que todo criador pense no público que deve receber sua obra, e esse público, como ele mesmo, está fortemente influído por uma linguagem cultural desenvolvido pela televisão e posteriormente o mundo da Internet. O dramaturgo e diretor alemão René Pollesch realizou uma das propostas mais criativas de assimilação da estética televisiva. Pollesch converte suas cenografias em amplos espaços rodeados com cômodos que lembram partes de um apartamento de uma grande cidade habitada por jovens: dinâmicos? Criativos? Alternativos? Os espectadores se acomodam nos estofados e colchões distribuídos entre o cenário. As peças se estruturam com base de diálogos que revisam de forma crítica e com frescor temas de atualidade, sem excluir o intranscendente e inclusive trivial. Os diálogos, que às vezes são lidos à vista do público, se precipitam em um ritmo enlouquecedor, acentuado por um elevado tom de voz, que termina conduzindo a uma espécie de hilariante caos estranhamente familiar ao espectador. Os atores se movem com rapidez de um lugar a outro dentro de uma sala iluminada por uma luz branca que coloca a atores e espectadores em um mesmo espaço e tempo. Tudo da a impressão de ser cotidiano e cálido, imediato e fragmentário, pois a peça vai saltando sem ordem de uns temas a outros, em um tom de espontaneidade e improvisação. A cultura urbana, estreitamente ligada aos meios, é levada ao seu extremo ao mesmo tempo em
${ }^{6} 0$ cinema surrealista e as vanguardas russas iniciaram uma poética que tornava visível o processo de montagem que constitui a atividade cinematográfica, atitude amplamente difundida a partir dos anos 70 por movimentos como a Nouvelle Vague, o Cinema Verdade, o Cinema Direto e, mais recentemente, por filmes como

Dogma e toda a obra de Lars von Trier, sem contar cineastas que mantém uma estreita relação com o fenômeno da teatralidade e com a plástica cenográfica, como o galês Peter Greenaway (Picon-Vallin, 1997; Cornago Bernal, 2001). 


\section{Urdimento}

que se rentabiliza criativamente, denunciando seus excessos. A partir deste modelo, o autor e diretor argentino Rafael Spegelburd desenvolveu uma série de peças com a forma de episódios de séries de televisão, Bizarra.

$\mathrm{Na}$ Espanha, depois do realismo social e das dramaturgias de corte popular, tem sido numerosos os autores (das últimas décadas) que desenvolveram formas dramáticas que seguem de perto os padrões televisivos, diálogos de intervenções curtas e cenas que se sucedem com rapidez, uma espécie de realismo urbano que trata igualmente de temas cotidianos, ainda que sua tradução teatral e expressividade dramática não se tenha traduzido em níveis altos de criatividade cênica. Nestes casos, a influência televisiva, que além da dramaturgia se estende também às linguagens atoriais e padrões de recepção do público, têm um caráter mais implícito, o que o faz menos visível.

Desde pré-supostos dramáticos não realistas, é importante destacar a estética violenta e fragmentária de Rodrigo García ou Roger Bernat já nos anos noventa, na linha de outros criadores europeus como Jan Fabre. Uma crítica violenta à sociedade de consumo é acompanhada normalmente com projeções de imagens sobrepostas que denunciam suas estratégias midiáticas. A este plano é oposta a presença dos atores, aparentemente privada de artifícios, e suas ações com um forte caráter performativo que trata de superar o nível da ficção, ações imediatas e ilógicas que contrastam com o mundo midiatizado, convenientemente ordenado para sua projeção a partir de uns interesses prévios. Desde uma poética comparável, Sara Molina desenvolve uma dramaturgia na qual se acentua o processual e fragmentário, a ação no seu transcurso sobre uma poética de restos que se opõe à imagem como resultado perfeito e acabado. Em todos estes casos a recorrência à performance supõe uma reação contra as realidades e os tempos diferidos, o corpo como resistência contra imagens construídas que se pretendem reais, um excesso não rentabilizado que denuncia realidades pré-fabricadas e uniformizadoras portadoras de uma adequada explicação do mundo. Este teatro pós-dramático denuncia o próprio conceito tradicional do tex to dramático como uma mediação ficcional a mais, potenciando a presença imediata do ator em contraste com as tramas construídas ou sua própria imagem projetada. Assim, por exemplo, Carlos Marqueríe, em 120 pensamientos por minuto (2002), utiliza um circuito fechado de vídeo para projetar sobre o fundo da sala a imagem dos atores, com o qual o espectador percebe ao mesmo tempo ambas realidades, o que no ambiente escuro da montagem, oferece um aspecto fantasmagórico. Em um nível superior de ficção, La Fura dels Baus, já desde o início dos anos oitenta, recorreu a projeções e música eletrônica para recriar o ritmo violento e o tom primitivo característico de certa cultura midiática. Mais recentemente este grupo se serviu de circuitos fechados de vídeo para mesclar de forma confusa imagens ampliadas do que ocorria na cena com outras previamente gravadas que 


\section{Urdimento}

fingiam estar ocorrendo, pondo ao serviço da cena a capacidade de manipulação dos meios. Em muitos destes casos, o vídeo fez possível uma visão de perto, produzindo uma impressão de tato, característica dos novos meios (MCLUHAN y POWERS, 1996), e inicialmente alheia ao olhar teatral clássico, incapaz de perceber pela distância os pequenos detalhes.

Com uma postura muito distinta, Robert Wilson representa uma das opções mais brilhantes de análise de um olhar amplo e totalitário, mas ao mesmo tempo capaz de reparar nos mínimos detalhes; unitária, mas ao mesmo tempo táctil e fragmentaria. Este olhar responde a um tipo de percepção que fez possível, pelas novas tecnologias, um ritmo lento e estranho que Wilson define como o ritmo autêntico da natureza (RICHTERICH, 1998; QUADRI, 1997). O corpo do ator parece dissolver-se na plasticidade bi-dimensional, e a unidade temporal se suspende na lentidão das ações cíclicas; no entanto, ainda que tudo pareça detido e irreal não deixa de estar em contínuo movimento. Wilson faz consciente o espectador de um tipo de percepção que de outro modo passaria inadvertido. Através de uma cena altamente estilizada, construída sobre movimentos precisos e uma partitura rítmica minuciosamente medida, ergue um mundo irreal, que graças a um complexo componente performativo não deixa de ter uma enorme teatralidade, que faz o difuso da cena ganhar uma maior presença imediata, tornando tangível este modo distinto de percepção.

\section{Diálogos explícitos com os meios}

Como vemos, a multiplicação das imagens na cultura midiática fez que uma grande parte da cena internacional, a partir dos anos setenta, tenha centrado-se na reflexão sobre os distintos tipos de imagens e suas formas de percepção; para isto os criadores da vanguarda destes anos, como Robert Lepage, Wooster Group, Squat Theater, John Jesurun, na América do Norte; na Itália, Societas Raffaello Sanzio, Falso Movimento ou Giorgio Barberio Corsetti, representantes do que se conheceu como a nuova spettacolarita, ou Ritsaert ten Cate, fundador em 1965 do Mickery Theatre de Amsterdam, só para citar alguns exemplos de um panorama muito mais amplo, converteram a cena em um laboratório de análise das tecnologias da imagem (LEHMANN, 1999). Comumente, imagem, som e movimento estão dissociadas, fazendo visível a construção que sustenta cada imagem e seus diferentes modos de percepção, como explica Jesurun, a partir de seu trabalho com os códigos das séries televisivas e a retórica do cinema: "Não se trata de compreender uma história, senão de como se compreendem as histórias" (apud SÁNCHEZ 1999: 179)7 .

Em uma linha paralela, Els Joglars não deixou de refletir sobre os diferentes tipos de teatralidade social e entre elas sobressaíram - como não podia ser de ser os protagonizados pelos meios de comunicação (BOADELLA, 2000). Por isso não é uma contradição que um grupo que tem reivindicado uma teatralidade artesanal Dezembro $2008-\mathrm{N}^{\circ} 11$

0 corpo invisível: teatro e tecnologias da imagem. Óscar Cornago Bernal.
7Junto a estes nomes, mas já plenamente no campo da performance e da vídeo-instalação, é necessário citar artistas que conseguiram um reconhecimento internacional, como Nam June Paik ou Laurie Anderson (Birringer 1998), e na Espanha Marceli Antúnez, o corpo reduzido a uma prolongação dos meios, capaz de transformar-se em um aparelho a mais da paisagem midiática, que controla com seus movimentos. 


\section{Urdimento}

${ }^{7}$ Em uma proposta comparável, ainda que de estética diversa, Adolfo Marsillach apresentou Antes que todo es mi dama, de Calderón de la Barca, como si se tratasse da filmagem de um filme antigo, o que serviu talvez para distrair 0 público de um modelo de encenação dos clássicos que por si só não parece muito atraente. baseada no trabalho de interpretação do ator no espaço vazio, tenha chegado a utilizar complexos meios áudio visuais, assim por exemplo como a enorme tela que funcionou como protagonista de algumas de suas últimas montagens, como se tratasse de um novo personagem. Em todos casos, o contraste entre a imagem midiática e a cena teatral tem servido para acentuar ambos pólos, isto é, a irrealidade pré-fabricada de uma e a realidade imediata da outra. Já em Teledeum (1983) se abordou o âmbito televisivo como espaço teatral; Ainda que o objeto final era a denúncia das religiões, a simulação do meio televisivo serviu para acentuar a teatralidade da proposta ao mesmo tempo que se fazia explícito o paralelismo entre estratégias midiáticas e doutrinais. Em sua última encenação, El retablo de las maravillas (2004), o grupo se volta para a televisão para convertê-la em um genuíno retábulo das maravilhas que mostra aos “cristãos velhos" do século XVII as maravilhas que haverá no futuro, expressadas convenientemente em atraentes imagens que aparecem neste tipo de retábulo tecnológico. Em um momento da fantástica visão uma espetacular modelo, expoente de uma das maravilhas das que haverá no futuro, escapa da tela para continuar sua passagem pela cena real, ante o olhar extasiado do comediante que vê com surpresa seu sonho feito realidade. O contraste entre o movimento estudado e a imagem impassível da atraente jovem com os gestos toscos e exagerados do bufão nos da indicação da conformação da realidade atual pelos meios e a aura com a que estes revestem o mundo. A transição das cenas se faz com uma progressiva debilitação dos atores como se fossem imagens manchadas que desaparecem do monitor quando se perde o sinal.

Com um olhar mais complacente La Cubana não deixou de utilizar tão pouco os códigos dos diferentes gêneros artísticos como estratégia de teatralização (DELGADO 2003: 225-274; MORALES ASTOLA, 2003). Assim, junto à linguagem da revista ou do teatro clássico, chegou a vez do cinema kitsch de Hollywood dos cinqüenta em Cegada de amor (1994). Estreada com honras de premier cinematográfica, está construída a partir do contraste frontal entre os códigos da tela e do mundo do teatro. A aparência distanciada, ficcional e fechada do filme acentua por oposição a dimensão teatral, seu caráter imediato em contato direto com o espectador, que fica convertido, como costuma acontecer em suas peças, em protagonista ativo da montagem midiático. O real e o fingido se confundem, como diz o estribilho da peça: "Neste mundo traidor nada é verdade nem é mentira", denunciando a codificação que subjaz a toda realidade. ${ }^{7}$

O diretor de cinema Juanma Bajo Ulloa fez uma interessante incursão no mundo teatral com a estréia em 1999 no cinema Lope de Vega de Madrid Pop Corn, sobre o texto de Ben Elton. Com a ajuda de um circuito fechado de vídeo o diretor faz visível os interesses que movem a televisão, fazendo o espectador responsável direto disso. Alternando cenas representadas com seqüências filmadas, e um fundo de música eletrônica e luzes de discoteca que davam as boas vindas ao público, a encenação conta a história de um seqüestro, 


\section{Urdimento}

cuja vítima, um famoso diretor de cinema que acaba de ganhar o Óscar, é ameaçado de morte se os índices de audiência neste preciso instante não caem. O "tele-espectador", sentado confortavelmente em sua casa, deve decidir entre salvar a vida da vítima, com o risco de perder o espetáculo, ou assistir ao vivo um assassinato real, deixando-se levar por esse desejo de ver que impulsiona a indústria midiática. A cara dos espectadores é refletida na enorme tela do fundo enquanto que o seqüestrador, que desceu até a platéia discute com o público gravando-os em vídeo: e o senhor, desligaria o televisor? Deste modo, a responsabilidade do espectador fictício é transpassada ao espectador teatral, convertido em responsável - culpado -, agora tornado visível, da montagem dos meios. ${ }^{8}$ Também Guillermo Heras em Rottweiler (2004), dirigida por Luis Miguel González Cruz, representa a realização de um programa de televisão no qual será entrevistado um perigoso jovem de extrema direita que, a partir das provocadoras perguntas do entrevistador para incendiar o ambiente, terminará com a vida do câmera depois de uma perseguição pelo estúdio/ palco. O público, incluído na encenação como espectadores do estúdio, pode seguir morbidamente a caçada humana através das câmeras que se supõe situadas nos corredores do estúdio. O homicídio, retransmitido ao vivo, será convenientemente rentabilizado pelo programa de televisão, que verá como aumentam seus índices de audiência convidando umas semanas mais tarde à noiva do jovem câmera para honrar sua memória.

\section{Conclusão: a encenação do olhar midiático}

As novas tecnologias formam parte já do milenário carro de Téspis e os exemplos seriam intermináveis. A inevitável distância de teatralidade que a cena aplica a tudo o que contém, nos fala de uma realidade cada vez mais construída através das imagens, e da duvidosa capacidade dos modos de percepção - igualmente construídos - para captar essa realidade. Finalmente, o que se está levando à cena não é uma imagem midiatizada, mas sim o olhar do espectador que corresponde a dito suporte midiático, o olhar cinematográfico, televisivo, fragmentada ou interativo construído por cada meio. O espectador se vê a si mesmo no ato performativo de olhar e fica surpreendido pelo modo tão distinto que impõe cada meio. A encenação da imagem cinematográfica, a montagem televisiva ou a velocidade dos links na Internet, ilumina um olhar e um comportamento cada vez mais midiatizado, essencialmente estético, isto é, mais subordinado a esses meios (de percepção). Tudo que ocupa um lugar na cena se reveste com seu manto de ilusão e engano, jogo e encenação, mas também assume a carga de realidade e ação imediatas, devolvendo ao sujeito sua responsabilidade política ao situar novamente a imagem no tempo e no espaço de sua produção, o que está oculto atrás de sua aparência acabada e perfeita. Deste modo, essas imagens, que fora da cena resultam verossímeis, agora, em contraste com a realidade imediata do corpo do ator, se revelam

\footnotetext{
${ }^{8}$ Com freqüência se utilizou o vídeo para conseguir um contato mais interativo com os espectadores, que se fazem presentes na cena por meio da imagem, especialmente no campo da performance e das instalações, como por exemplo, nos últimos trabalhos de Olga Mesa e sua dramaturgia de presenças e ausências, à que contribuem os jogos com o vídeo e as imagens detidas.
} 


\section{Urdimento}

como resultado de um processo químico ou eletrônico, recebido por um olhar treinado para percebê-lo como realidade, resultado de uma montagem movida por uns interesses econômicos e políticos.

Finalmente, o mito por excelência da Modernidade, a chamada autenticidade, aparece como uma categoria questionável, quando não altamente suspeita: os meios como a encenação dessa autenticidade(FISCHER-LICHTE, 2000; AUSLANDER, 1999; KEMAL y GASKELL, 1999). O caráter sempre excessivo da cena, sua dimensão material e performativa, põe de manifesto a manipulação a que está submetido olhar midiática, limpa, recortada e atraente, quando termina percebendo as imagens projetadas como mais reais que aquilo que vê na cena. A forma de cada meio se converte em uma parte da mensagem teatral, e o teatro termina questionando não já a percepção característica de cada um, mas sim a percepção da percepção, os bastidores que sustentam cada modo de olhar. Como uma arte política e capaz de fazer uma crítica imanente a partir de suas próprias formas, o teatro segue falandonos das substâncias que articulam as realidades, de seus ritmos e formas de representação. O espaço teatral e seu olhar de descrédito nos descobrem também o teatro midiático que se esconde detrás de cada meio e a encenação do olhar cúmplice que o sustenta.

\section{Referências bibliográficas}

AA.VV. Théâtre et télévision. Toulouse-Le Mirail, Université de Toulouse-Le Mirail, 1979.

ALCÁZAR, Josefina. La cuarta dimensión del teatro: tiempo, espacio y vídeo en la escena moderna. México: Instituto Nacional de Bellas Artes/Centro Nacional de Investigación, 1998.

AUSLANDER, Philip. Liveness. Performance in a mediatized culture. London/ New York: Routledge, 1999.

BAUDRILLARD, Jean. La ilusión y la desilusión estéticas. Caracas: Monte Ávila, 1998.

BIRRINGER, Johannes. MediaङPerformance. Along The Border. Baltimore/ London: The Johns Hopkins University Press, 1998.

BOADELLA, Albert. El rapto de Talía. Barcelona: Plaza\&Janés/Nuevas Ediciones de Bolsillo, 2000.

BREA, José Luis. La era postmedia. Acción comunicativa, prácticas (post) artísticas y dispositivos neomediales. Salamanca: Consorcio de Salamanca/ Centro de Arte de Salamanca, 2002.

CORNAGO BERNAL, Óscar. "Relaciones estructurales entre el cine y el teatro: De la categoría del montaje al acto performativo". Anales de la Literatura Española Contemporánea, 26. 1, 2001. pp. 65-91. 
(2002), "Diálogos a cuatro bandas: teatro, cine, televisión y "teatralidad", en Del teatro al cine y la televisión en la segunda mitad del siglo XX, eds. José Romera Castillo y Francisco Gutiérrez Carbajo. Madrid, Visor, pp. 549-560.

DELGADO, Maria M. (2003), 'Other' Spanish Theatres. Erasure and Inscription on the Twentieth-Century Spanish Stage. Machester, Manchester University Press.

FISCHER-LICHTE, Erika. Inszenierung von Authentizität. Tübingen: Francke, 2000. .Wahrnehmung und Medialität. Tübingen/Basel: Francke, 2001.

GONZÁLEZ REQUENA, Jesús. El discurso televisivo: espectáculo de la posmodernidad. Madrid: Cátedra, 1999.

GÖTTLICH, UDO, Jörg-uwe Nieland y Heribert Schatz. Kommunikation im Wandel. Zur theatralität der Medien. Colonia: Herbert von Halem, 1998.

ESSLIN, Martin. Le théâtre anglais d'audjourd'hui et les mass media. Au-déla de l'absurde. Paris: Éditions Buchet/Chastel, 1970. pp. 323-337.

KEMAL, Salim; GASKELL, Ivan. Performance and authenticity in the arts. New York: Cambridge UP, 1999.

LEHMANN, Hans-Thies. Postdramatisches Theater: Essay. Frankfurt am Main: Verlag der Autoren, 1999.

MCLUHAN, Marshall Y B. R. Powers. La aldea global. Transformaciones en la vida y los medios de comunicación mundiales en el siglo XXI. Barcelona: Gedisa, 1996.

MORALES ASTOLA, Rafael. La presencia del cine en el teatro. Antecedentes europeos y su práctica en el teatro español. Sevilla: Ediciones Alfar, 2003..

PAVIS, Patrice. El análisis de los espectáculos. Teatro, mimo, danza, cine. Barcelona: Paidós, 2000.

PICON-VALLIN, Béatrice. Le film de théâtre. Paris: CNRS, 1997.

POSTMAn, Neil. Amusing Ourselves to Death. Public Discourse in the Age of Show Business. London: Methuen, 1987.

QUADRI, Franco. Vie et temps selon Robert Wilson en Robert Wilson. Paris: Éditions Plume,1997. pp. 9-64.

RICHTERICH, Uwe. Die Sehnsucht zu sehen. Der filmische Blick auf dem Theater. Robert Wilsons the CIVIL wars. Frankfurt am Main: Peter Lang, 1993.

SÁNCHEZ, José A. Dramaturgias de la imagen. Cuenca: Universidad de Castilla-La Mancha, 1999.

ZUNZUNEGUI, Santos. Pensar la imagen. Madrid: Cátedra/Universidad del País Vasco, 1995. 